\title{
A regenerative concept for thermoelectric power generation
}

Shouyuan Huang ${ }^{1}, \mathrm{Xianfan}_{\mathrm{Xu}}{ }^{1, *}$

1-School of Mechanical Engineering and Birck Nanotechnology Center, Purdue University, West Lafayette, IN, USA

*Corresponding Author. Email: xxu@ecn.purdue.edu, Phone: (765) 494-5639

\section{Abstract}

This paper presents a regenerative concept for thermoelectric (TE) based waste heat recovery systems called thermoelectric generators (TEGs). TEG is usually a modified heat exchanger with the addition of thermoelectric modules (TEMs) to recover waste heat for power generation. To utilize heat from high temperature heat sources, current researches have largely been focused on the development of high temperature TE materials. In this study, we describe a regeneration concept in which a precooler is used to lower the temperature of the hot gas and at the same time regenerate hot air from the cold air supply for $\mathrm{Bi}_{2} \mathrm{Te}_{3}$-based TEGs, avoiding the use of hightemperature thermoelectric materials. It is found that the regenerative TEGs can achieve a similar power output compared with TEGs using high temperature TE materials such as filledskutterudites (combined filled skutterudites and $\mathrm{Bi}_{2} \mathrm{Te}_{3} \mathrm{TE}$ materials) through obtaining a higher heat scavenging rate. Thus, the regenerative TEGs also have a similar absolute efficiency, defined according to the total available enthalpy from the hot gas. This could represent a paradigm shift in the TEG research and development, that much lower-cost, reliable, and readily available TE materials and modules can be used for high temperature applications, and will ultimately enable wide spread deployment of TEGs for real world waste heat recovery applications. 
Keywords: Thermoelectric generators, regeneration, waste heat recovery, bismuth telluride.

\section{Introduction}

The increasing demands on energy and the concerns on fuel shortage and carbon emission have drawn attentions to the recovery of waste heat, which is abundant from vehicle exhaust to power plants and industrial furnaces. These waste heat sources may vary within a wide temperature range from just above the room temperature to over $1000^{\circ} \mathrm{C}$. Among methods of waste heat recovery, thermoelectric generators (TEGs) are featured with direct conversion to electricity, high reliability without moving parts or special working fluids, and no vibration or noise emission. Over decades of research and development, a wide spectrum of thermoelectric materials, including more recent developments of nanostructured materials have been discovered and synthesized to achieve high figure-of-merit $Z T$, defined as $\alpha^{2} \sigma T / k$ with $\alpha, \sigma, k$, and $T$ being the Seebeck coefficient, electrical conductivity, thermal conductivity, and absolute temperature, respectively, for a wide temperature range from sub-room-temperature to over $1000^{\circ} \mathrm{C}[1-5]$.

Numerous efforts have been devoted into developing TEG applications [6-20], mostly focused on but not limited to engine and industrial waste heat recovery. Design calculations were carried out to improve the performance of power output/efficiency, reliability, and costs, and also evaluate the trade-off among these parameters. Numerical modeling made it possible to investigate these factors in a fast and economical manner [21-29]. Many research efforts have been dedicated to the development of high temperature TE materials [2,3,30-34] for converting high temperature heat sources to power, and achieving high ZT [34,35]. Up till now, however, there are no reliable high temperature TE modules made commercially available. The large 
thermal stress of materials at high temperature and chemical instability, which often result in the requirements of using inert gas or vacuum encapsulation [36] in the TE module and the TEG, are just some of the main barriers of using these materials. Although there are high temperature TEG demonstrations $[6,8,14,15,17,19,20,37]$ and designs particularly addressing reliability or costs $[10,38]$, in general, implementing a high temperature TEG poses much greater engineering challenges. On the other hand, low temperature TEGs are much more reliable and ready to use $[22,35,39,40]$

In addition to efficiency and reliability, the cost-performance analysis is also key for the commercial feasibility of a TEG. Cost-effective analyses have been carried out to illustrate the competitiveness of TEGs to improve fuel efficiency [41,42], and cost-per-watt [43] is often used for TEGs evaluation. It was also found that the commercial barriers of using high-temperature TE material are largely the system costs $[44,45]$. However, lacking sufficient data on the costs of manufacturing high-temperature modules and high temperature TEGs, accurate system cost estimations are yet to be conducted. It is also noted that the cost of materials usually accounts for about $10 \%$ of a high-temperature TEG, indicating the choice or processing of materials are not the promising direction for lowering the overall TEG cost though some reductions can be made [44].The transient performance [46], electrical connection [47], etc. are also important factors for the TEG engineering realization. However, it is only meaningful to consider these factors after the cost-effectiveness and reliability proven to be acceptable by the market.

The concept of regeneration has been accepted in varieties of thermal systems, including Stirling engines, absorption cooling system, and especially combined turbine cycles. Taking advantage of high performance heat exchangers, regeneration produces additional lower temperature heat sources and thus improves the efficiency by a noticeable amount. However, this useful and 
practical concept has yet to be applied or investigated for thermoelectric power generation. In this work we introduced the regeneration concept to the area of TEG and proposed the regenerative thermoelectric generator (R-TEG) for recovering power from high temperature waste heat sources, using entirely low temperature TE materials to circumvent the complications of manufacturing a high temperature TEG.

The proposed R-TEG first cools the hot gas to a temperature acceptable by low temperature TE modules, and simultaneously raises the temperature of a stream of cold ambient air. Both the cooled hot gas and the heated air are then fed into the TEGs that use low temperature TEMs $\left(\mathrm{Bi}_{2} \mathrm{Te}_{3}\right.$ modules are used in this study). Two types of regeneration designs are studied using the previously established numerical methods [48,49] and the optimization algorithm [50]. For comparison, the power outputs from a high temperature TEG using combined filled-skutterudite and $\mathrm{Bi}_{2} \mathrm{Te}_{3}$ TEMs (referred to as high-T TEG in this work) are computed. It is found that the regenerative TEG can achieve similar performance as the high-T TEG. For waste heat recovery, the goal is to maximize the power output with a given amount of waste heat source. The absolute efficiency, defined as ratio of the power output and the available enthalpy from the heat source, is an indicator of the TEG performance. Therefore, the regenerative TEGs have a similar absolute efficiency compared with the ones using high temperature TEMs. A cost analysis of RTEGs is also performed. The reason for the high performance of the R-TEG is analyzed, and is proven to be consistent with the existing TE generation theory. Given the tremendous benefits of using low temperature TEMs for the R-TEG, including much lower-cost, reliability, and availability, the development of R-TEGs will represent a paradigm shift in the TEG research and development, and will ultimately enable the wide spread deployment of TEGs for real world waste heat recovery applications. 


\section{Description of R-TEG}

The R-TEG is designed based on a counter flow heat exchanger as shown in the gas flow chart in

Fig 1. We assume the waste heat source is hot gas (air) at $800 \mathrm{~K}$ with a mass flow rate of 0.1 $\mathrm{kg} / \mathrm{s}$, and the room temperature air $(300 \mathrm{~K})$ is the coolant. The hot gas first enters a gas phase heat exchanger called precooler, to cool to a temperature that is acceptable for $\mathrm{Bi}_{2} \mathrm{Te}_{3}$ modules. In this work, we limit the hot side junction temperature of the $\mathrm{Bi}_{2} \mathrm{Te}_{3} \mathrm{TEMs}$ to be lower than 550 $\mathrm{K}[40]$. The cooled hot air then enters a $\mathrm{Bi}_{2} \mathrm{Te}_{3}$-based TEG labeled as sub-TEG1 in Fig. 1.

For comparison, we also compute and optimize conventional high-T TEGs, where filledskutterudite modules are used in the higher temperature sections and $\mathrm{Bi}_{2} \mathrm{Te}_{3}$ modules at the lower temperature sections. The hot side junction temperatures of $\mathrm{Bi}_{2} \mathrm{Te}_{3}$ modules in these high- $\mathrm{T}$ TEGs are also kept below $550 \mathrm{~K}$. The detailed parameters of the two types of TEMs are taken from Ref. [49].

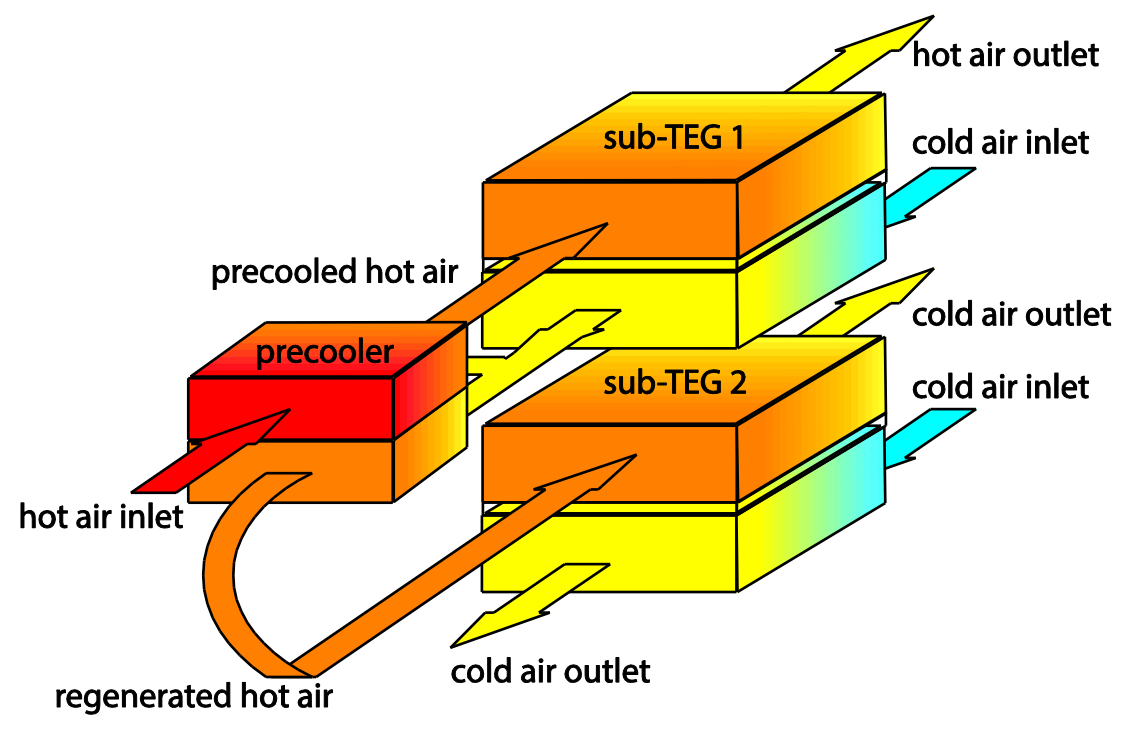

Fig. 1 Schematics of an R-TEG (R-TEG 1). 
In our R-TEG design, the cold air that is used to cool the hot air in the precooler comes from TEG1 in order to recycle (regenerate) more heat as shown in Fig. 1. The regenerated hot air is then fed into a second $\mathrm{Bi}_{2} \mathrm{Te}_{3}$-based TEG (sub-TEG2) to produce more power. The amount of the cold air used for the precooler is chosen such that the temperature of the output of the warmed cold air reaches the limit for being used in sub-TEG 2, i.e., the same as the inlet temperature for sub-TEG 1. The size and the cold air supply for sub-TEG 2 are thus proportional to those of the sub-TEG 1 according to the mass flow rate of the regenerated hot air.

A second R-TEG design is illustrated in Fig. 2. Instead of using a fraction of the cold air from sub-TEG1 for the precooler, the regenerated air continuously flows in a closed loop as shown in Fig. 2. One of the advantages of using the closed loop is that other types of heat carrying fluid can be used, for example, liquid coolant, to significantly enhance the heat transfer rate, resulting in more power output from sub-TEG 2. However, the calculations below are based on air as the regenerating fluid.

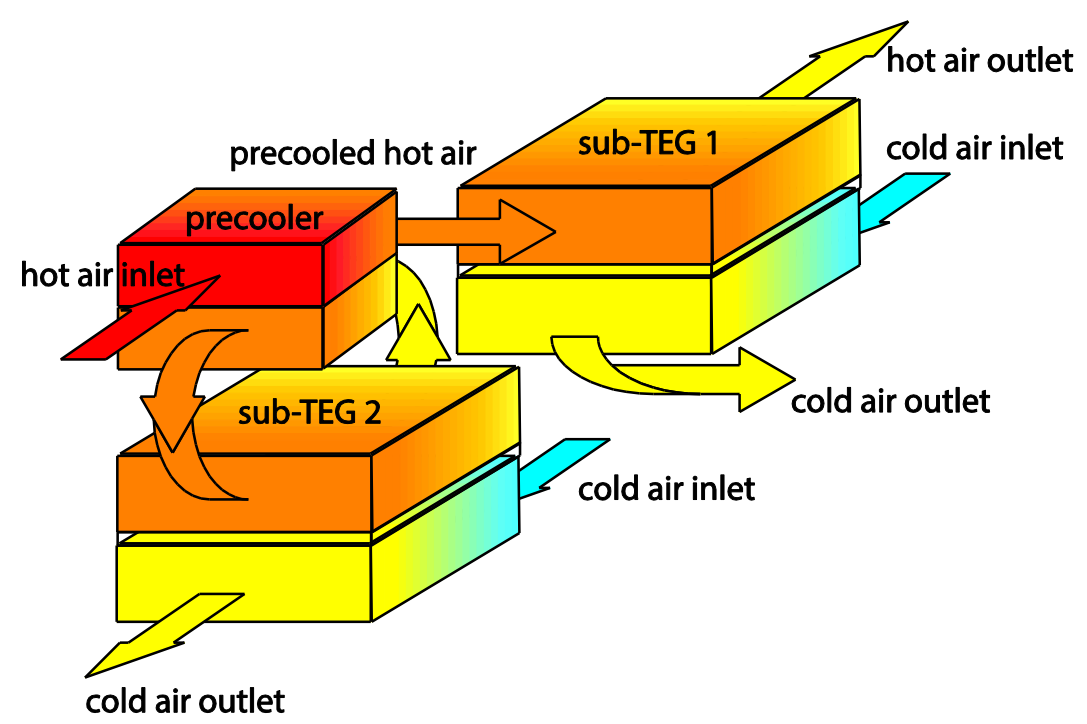

Fig. 2. Flow chart of regeneration concept 2 (R-TEG 2). 
The computational model, materials properties, and optimization method for the TEGs are adapted from previous works [48-51]. The precooler is calculated using the $\epsilon-\mathrm{NTU}$ method [52]. For the TEGs, there are three major design parameters used in our study: the heat exchanger area $\left(A_{H E}\right)$, the aspect ratio (width/length), and the height of TEC legs $\left(H_{T E}\right)$. These are the basic geometric parameters of the heat exchangers and TEMs that govern the heat transfer rate and junction temperature difference, and thereby determine the power output. The aspect ratio of the heat exchanger has less an effect on the power output according to the sensitivity analysis [50]. In additional to the aforementioned parameters, the fill factor of the TEM, i.e. the TE material coverage over the total heat transfer area, is held as constant according to the TEM designs for two materials respectively from previous works $[48,49]$. Thus, the heat exchanging area and height of TEM legs are the only two dominant parameters of the TEG performance for this study. The width of the heat exchanger channel is selected to be $0.27 \mathrm{~m}$. $A_{H E}$ (= $0.27 \mathrm{~m} \times$ length) and $H_{T E}$ are selected as the optimization factors with upper bounds set at 0.2 $\mathrm{m}^{2}$ and $8 \mathrm{~mm}$, respectively. In addition to the power output, the heat dissipation rate from the hot gas is another key parameter to be evaluated. The hot side convection coefficient is set to a constant $2700 \mathrm{~W} / \mathrm{m}^{2} \mathrm{~K}$ based on a typical intermittent corrugated plate heat exchanger [53], and the cold side convection coefficient varies according to Eq. (1) with $\mathrm{h}_{0}=2300 \mathrm{~W} / \mathrm{m}^{2} \mathrm{~K}$. The index 0.35 in Eq. (1) is taken from the regression of a similarly structured heat exchanger [53] according to its dependence on the Reynolds number $R e$.

$$
\mathrm{h}=\mathrm{h}_{0}\left(\frac{R e}{R e_{0}}\right)^{0.35}=\mathrm{h}_{0}\left(\frac{\dot{m}}{\dot{m}_{0}}\right)^{0.35}
$$




\section{RESULTS AND DISCUSSTION}

The TEGs with different design concepts are optimized to provide the maximum power output. We first assume there is abundant room temperature air for cooling and the calculations are carried out with cold air supply up to 30 times of that of the hot air (after which the output power does not change much as seen below).

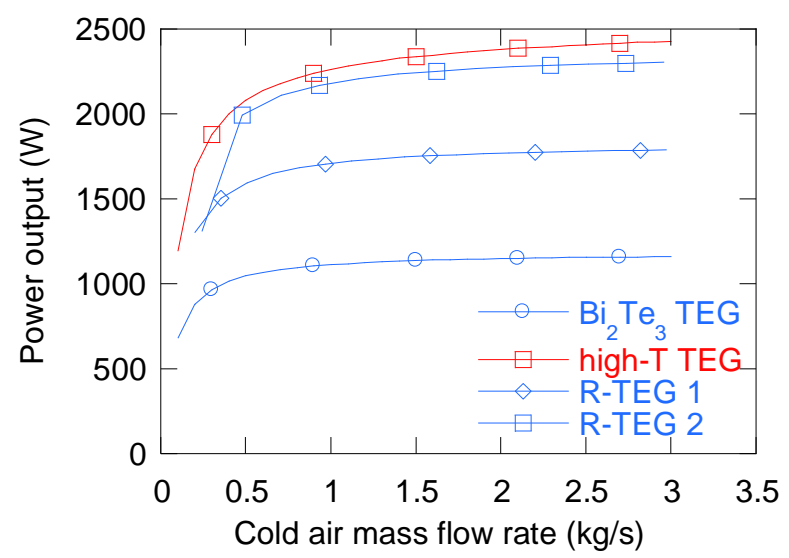

Fig. 3. Optimized power output of TEGs with different designs under varied cold air supply.

Figure 3 compares the optimized power output for high-T TEG, R-TEG 1 and R-TEG 2 vs. the cold air supply. In addition, the power output from using the $\mathrm{Bi}_{2} \mathrm{Te}_{3}$ TEG alone (sub-TEG 1 in the R-TEGs) is also shown. It can be seen that high-T TEG, R-TEG 1 and R-TEG 2 have similar power outputs when the cold air mass flow rate is low. With more cold air supplied, the power outputs increase, and the power outputs from high-T TEG and R-TEG 2 increase more than that from R-TEG 1. Notably, R-TEG 2 generates similar amount of power compared with high-T TEG, even for high cold air supply rates.

The main advantage of our proposed design is that the cost can be lower. Here we conduct a rough price comparison of the high-T TEGs and the proposed R-TEG 2. Our estimation of the 
module cost is based HZ-20 from Hi-Z Technology Inc. and PBTAGS-200.009A from TECTEG FMR, for low and high-temperature modules, respectively. The cost of heat exchangers for TEGs is estimated from Ref. [45] and is $7.6 \$ /(\mathrm{W} / \mathrm{K})$. The cost of precooler $(1 \$ /(\mathrm{W} / \mathrm{K}))$ is interpolated from the data of a typical recuperator from Ref. [54]. The cost of high-temperature TEMs is expected to become lower in the future. On the other hand, the additional costs of building the high-T TEG including thermal packaging/insulation, high-temperature electronic circuits, mechanical sealing, etc. are not included as there are no available data, but are expected to be high from our prior experience. The estimated TEG costs are plotted in Fig. 4. The costs for the heat exchanges (HEX) alone are also shown in Fig. 4. It is seen that most of the cost of an RTEG is ascribed to the heat exchangers. Therefore, the cost competitiveness of an R-TEG lies in its much lower TEM manufacturing cost. Note that the heat exchanger cost of an R-TEG is about twice of that of a high-T TEG at a same coolant supply, owing to its overall larger size.

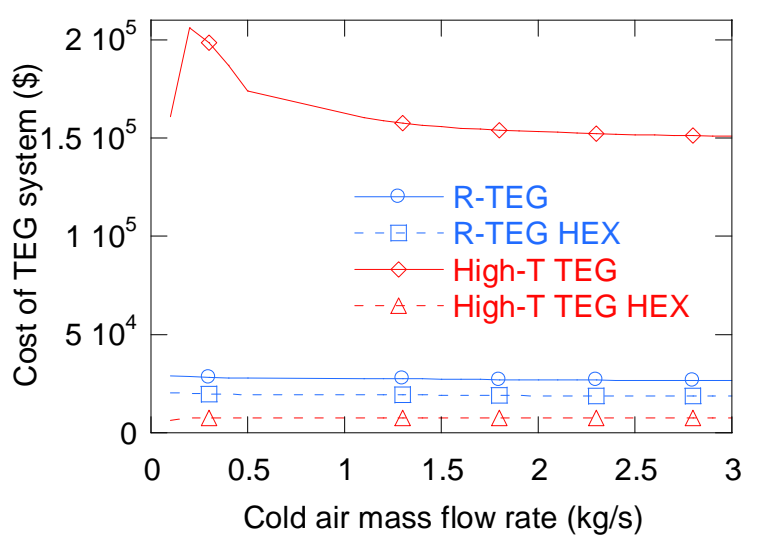

Fig. 4. Cost of the entire systems and the heat exchangers with high-T TEG design and RTEG 2 design.

As the cost of the R-TEG is largely determined by its size, we further looked into the potentials of improving its cost effectiveness by limiting the total heat exchanger area. Figure 5 shows the 
heat exchange area vs. output power and system cost. The green line represents the case $\dot{m}_{c}=1.16 \mathrm{~kg} / \mathrm{s}$ shown previously in Figs. 3 and 4 , where the total area is $0.463 \mathrm{~m}^{2}$. It can be seen that $90 \%$ of the power can be achieved by a system that is $40 \%$ smaller or the costs are $40 \%$ less. The design with the minimized cost-per-watt is found to have a total $A_{H E X}=0.12 \mathrm{~m}^{2}$ and costs \$7.0/W. The high-T TEG can be similarly reduced by limiting the heat exchanger size. However, there is less room for the cost-effectiveness improvement due to the present high module cost.

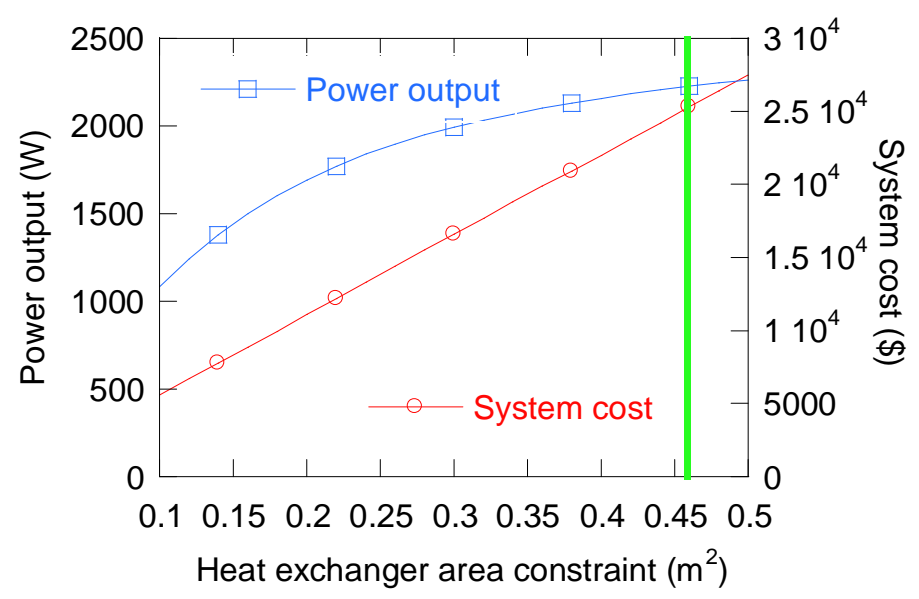

Fig. 5. System costs and power output under different heat exchanger area constraints. $\dot{m}_{c}=1.16 \mathrm{~kg} / \mathrm{s}$. Green line indicates the corresponding case shown in Figs. 3 and 4.

We also estimate the cost of coolant supply and regenerative pump power based on the energy consumption, assuming the cold air supply at ambient temperature is abundant. The friction coefficient is obtained from regression calculations [53] to estimate the pressure drop,

$$
f=5.2073 \times R e^{-0.71},
$$

and then the pump power is estimated as the product of the pressure drop and the volumetric flow rate. The net power output from TEGs after subtracting the power needed to pump the cold air and regenerated air is then calculated and shown in as solid lines in Fig. 6. It is seen that the 
net power output of the R-TEG 2 is generally higher than the high-T TEG except when coolant supply is about $0.5 \mathrm{~kg} / \mathrm{s}$ ( 5 times of hot air mass flow rate) where both high T-TEG and R-TEG outputs most of the power or net power. For cold air flow rates higher than $0.5 \mathrm{~kg} / \mathrm{s}$, the power output of the R-TEGs drops slower because the same amount of air is flowing through the wider scaled-up channels in R-TEGs, resulting in lower flow velocity and thus a lower pressure drop.

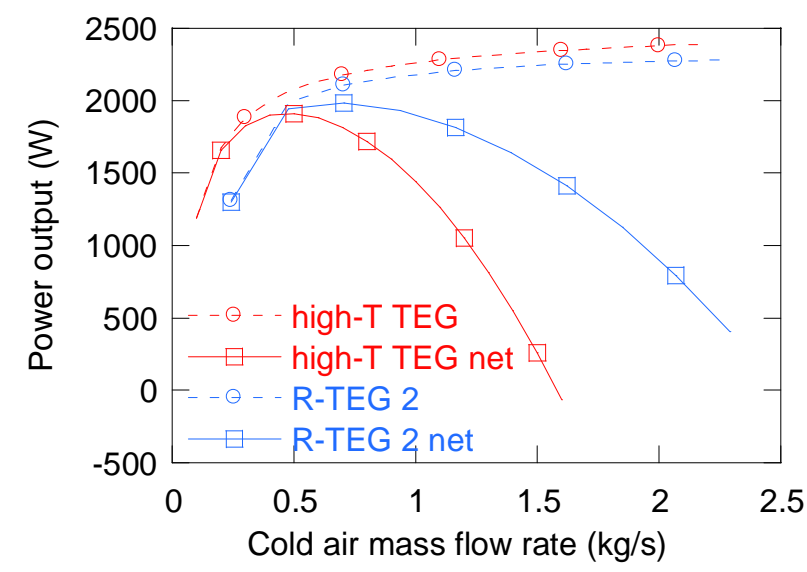

Fig. 6. Comparison of the high-T TEG and R-TEG 2 performances with respect to the costs of coolant supply.

We now analyze why R-TEG 2 can achieve similar power output compared with the high-T TEG which converts heat to power at higher temperatures. It is known that the efficiency of converting heat to power is related to (or limited by) the Carnot efficiency, which is higher at higher operation temperature as shown in Eq. (3):

$$
\eta_{C}=1-\frac{T_{c}}{T_{h}}=\frac{\Delta T}{T_{h}}
$$

The main reason that a lower temperature R-TEG 2 can achieve similar power output is due to the larger heat transfer rate. The averaged Carnot efficiencies and heat transfer rates are plotted respectively in Figs. 7(a) and 7(b). The averaged Carnot efficiency is calculated based on local 
junction temperatures weighted by the local heat flux. It is seen that the averaged Carnot efficiency of R-TEG (the Carnot efficiency for R-TEG 1 and R-TEG 2 are the same) is significantly lower than that of the high-T TEG. On the other hand, it is seen from Fig. 7(b), that with the generative design, R-TEG 2 is capable to scavenge more heat from the hot gas than the high-T TEG. Comparing R-TEG 2 and R-TEG 1, R-TEG 2 produces high power due to the closed loop design and the resulting higher regenerated mass flow rate. The regenerated mass flow rates $\left(\dot{m}_{r}\right)$ of R-TEG 2 and R-TEG 1 are shown in Fig. 8. It is seen that the regenerated mass flow rate of R-TEG 2 is much higher than that of R-TEG 1. 

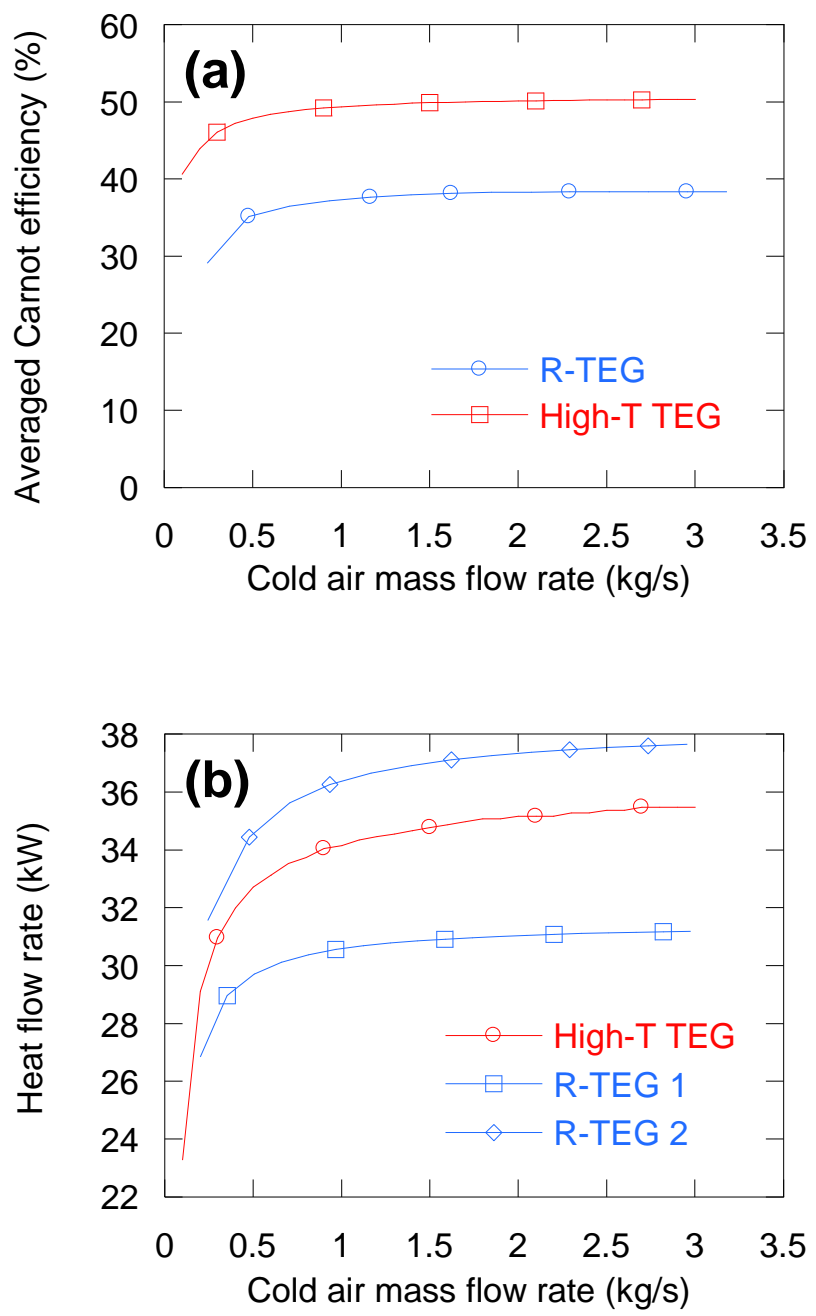

Fig. 7. (a) The averaged Carnot efficiency of TEGs of different designs and working condition under varied cold air supply when the power output is optimized. (b) Heat transfer rate of different designs under varied cold air supply, when the power output is optimized. 


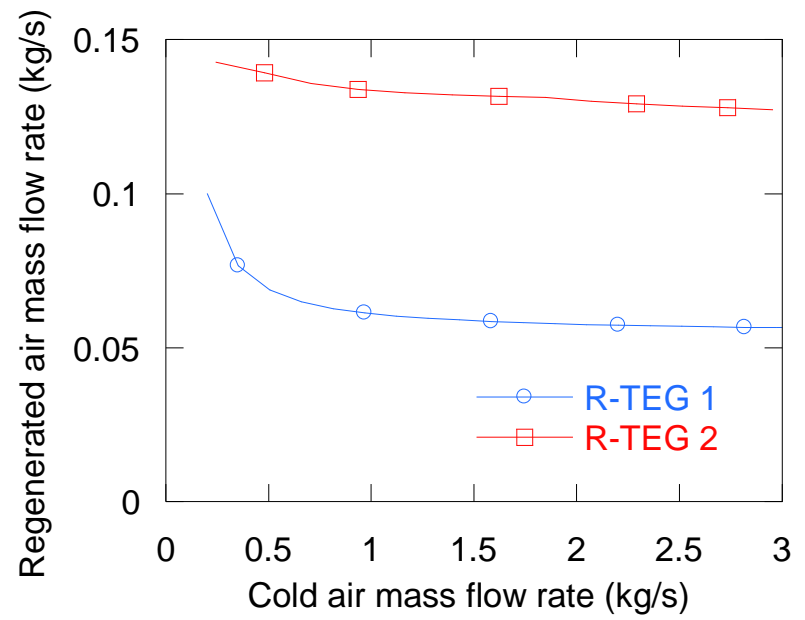

Fig. 8. Regenerated air mass flow rate of TEGs of different designs and working condition under varied cold air supply, when the power output is optimized.

The power output is a combined effect of the Carnot efficiency, the heat transfer rate, and $Z T$ as shown in Eq. (4) [55]. For the materials used in this study, $Z T$ of $\mathrm{Bi}_{2} \mathrm{Te}_{3}$ varies in the range from 0.83 to 0.96 [40], while $Z T$ of materials used in high-T TEGs are shown in Fig. 9. Although the value of $Z T$ of the skutterudites varies with temperature [56,57], it is seen that the averaged $Z T$ s are in a similar range as that of $\mathrm{Bi}_{2} \mathrm{Te}_{3}$. Thus, $Z T$ is a less influencing factor for the power outputs.

$$
\begin{gathered}
W=\eta Q \\
\eta=\eta_{C} \times \frac{\sqrt{1+Z \bar{T}}-1}{\sqrt{1+Z \bar{T}}+T_{c} / T_{h}} \\
\bar{T}=\left(T_{c}+T_{h}\right) / 2
\end{gathered}
$$




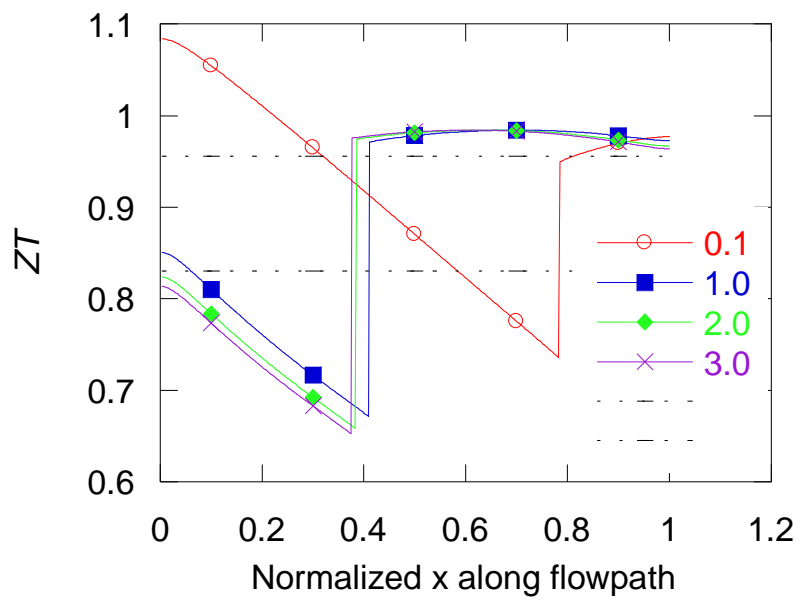

Fig. 9. Local $Z \bar{T}$ of TE materials in high-T TEGs along the flow path. For $\dot{m}_{\mathrm{c}}=0.1,1.0,2.0$, $3.0 \mathrm{~kg} / \mathrm{s}$.

Our results of power output using numerical models are consistent with simple estimations using Eq. (4). To compare with the calculated data shown in Fig. 3, the power output is calculated again using Eq. (4) based on the local junction temperatures and heat transfer rate. The results are compared in Fig. 10. It is seen that the results obtained using Eq. (4) are close to that from the numerical model. There are two reasons contributing to the slight discrepancy between the results of the two methods. One is that using the material properties evaluated by the mean temperature (which is used for $Z \bar{T}$ ) results in a higher power output than using integral averaged properties [51], which is the method we used in the model [50]. Also, $Q$ in Eq. (4) is a weighted average of the heat transfer rate along the TEC legs and its value lies in between of the heat enters and leaves the TEM. While in the calculations we used the heat transfer rate that enters the TEM, which also results in a higher power output. 


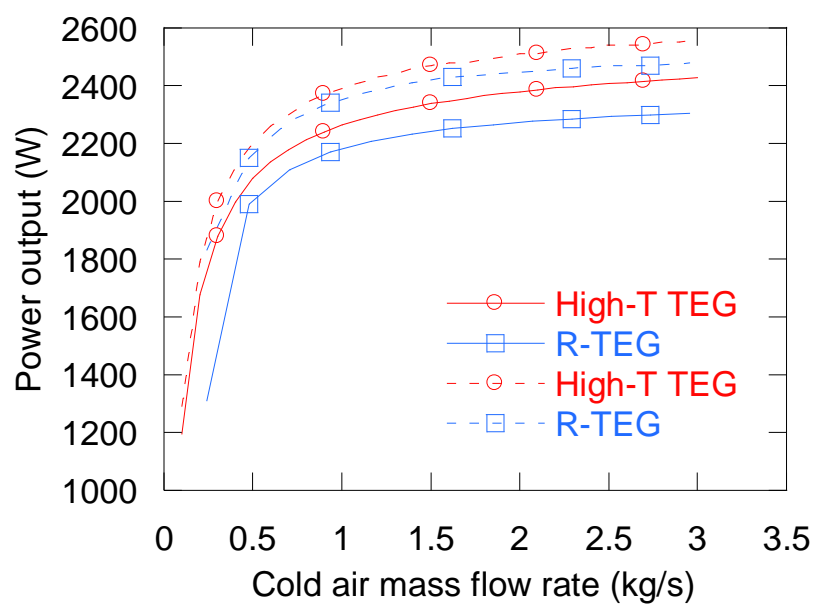

Fig. 10. Power output calculated by the numerical model and Eq. (4). Solid lines are results using numerical model; dashed lines are results obtained using Eq. (4).

We further analyze $1^{\text {st }}$ Law efficiencies and absolute efficiencies of the high-T TEG and R-TEG 2, and compare them in Fig. 11. The $1^{\text {st }}$ Law efficiency is defined in Eq. (4b). The absolute efficiency is based on the available enthalpy of heat source with respect to the ambient temperature, as defined in Eq. (5), which also evaluates the energy scavenging capability in additional to the energy conversion. $h_{\text {hot, in }}$ and $h_{0}$ are enthalpies of air at hot inlet and ambient conditions.

$$
\eta_{a b s}=\frac{W}{\dot{m}_{C}\left(h_{h o t, i n}-h_{0}\right)}
$$

It is seen that generally R-TEGs have lower $1^{\text {st }}$ Law efficiencies, though not as low as their averaged Carnot efficiencies. However, our R-TEG designs provide better energy scavenging capabilities that can compensate for the lower $1^{\text {st }}$ Law efficiencies. It is seen that the R-TEGs have comparable absolute efficiency compared with that of high-T TEGs. Hence, similar amount of power can be extracted from an R-TEG as from a high-T TEG. 

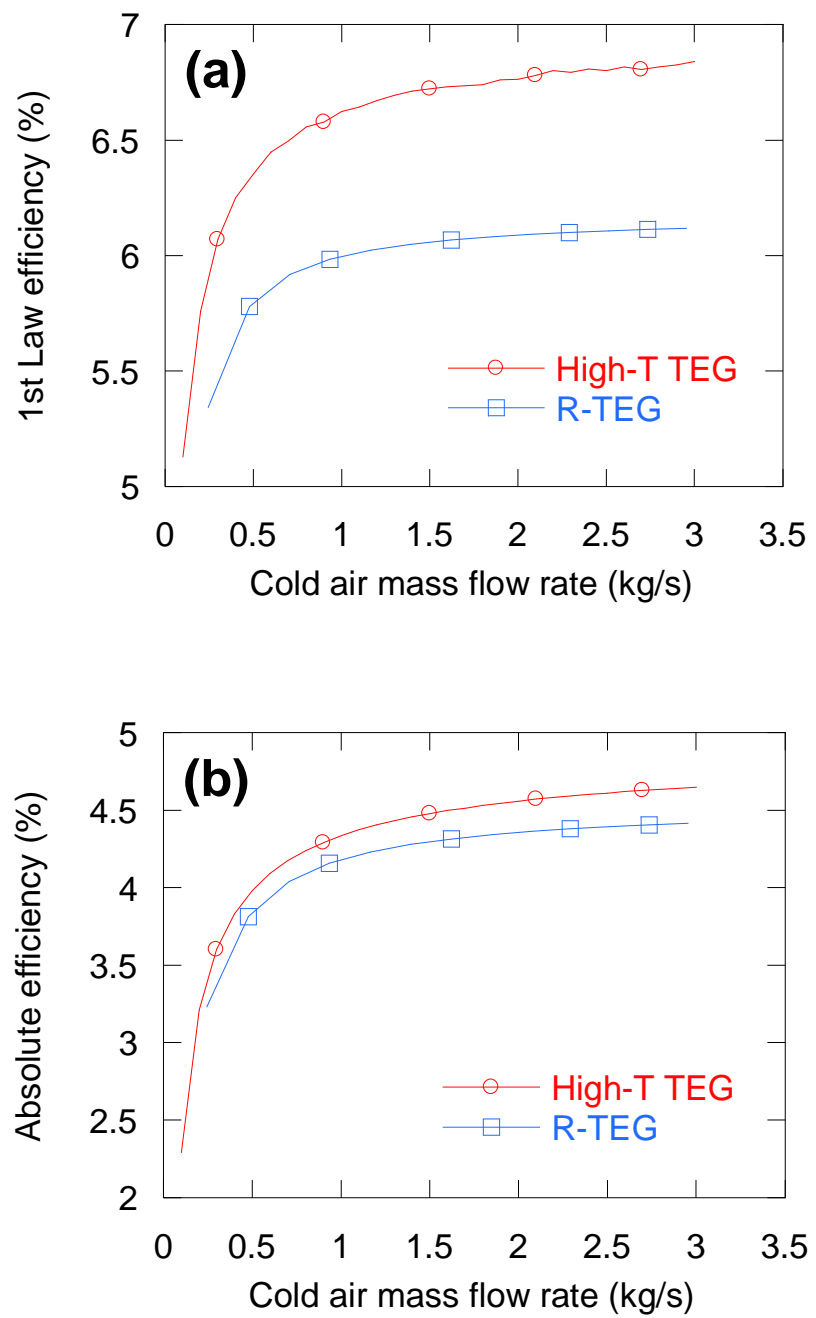

Fig. 11. Efficiencies of high-T TEG and R-TEG 2. (a) $1^{\text {st }}$ Law efficiency; (2) absolute efficiency.

The parameters studied showed their significance. The area of heat exchanger simply indicates the scale of the TEG that varies according to the amount of hot air. The ratio between the leg height and the filled area determines the thermal resistance which determines the trade-off between heat transfer rate and temperature difference, and has a significant impact on the TEG performance. In this work, the filled factor is held as constant as in previous works [48-50] (0.631 for $\mathrm{Bi}_{2} \mathrm{Te}_{3}$ modules, 0.397 for filled-skutterudite modules). Thus, the heat exchanging 
area and the height of TEG legs are the two parameters for the current study. The averaged intrinsic thermal resistance of TEMs in comparison with the total thermal resistance across $(1 / U A)$ the TEG is plotted in Fig. 12 (a). Notice that the optimized TEM thermal resistance is not close to $1 / 2$ of the total thermal resistance. For the TEGs operating between two constant temperature reservoirs, the optimized TEM resistance is $1 / 2$ of the total resistance according to Eq. (6), in which $R_{\text {pack }}$ is the thermal resistance other than $R_{T E M}$ in the TEG. However, in the cases of gas phase heat exchanger based TEGs studied here, the temperatures of the hot and cold gasses are not constant. The decrease in the temperature difference between the hot and cold air reduces the heat transfer rate, which is equivalent to additional thermal resistances if we compare it with the constant temperature reservoir formulation. Thus, the $R_{T E M, o p t}$ is to match up with the combined $R_{p a c k}$ and the equivalent thermal resistor to obtain the maximized power output.

$$
=\frac{\left(T_{H}-T_{C}\right)^{2}}{T_{H, j}} \times \frac{1}{\frac{R_{\text {pack }}^{2}}{R_{T E M}}+\eta_{T E M}+2 R_{\text {pack }}}
$$

In Fig. 12 (b), we show power output vs. resistance for one case $\left(\dot{m}_{c}=1.16 \mathrm{~kg} / \mathrm{s}\right)$, and the optimized $H_{T E}$ is $7.0 \mathrm{~mm}$ and the corresponding (also optimized) thermal resistance is 0.01247 $\mathrm{K} / \mathrm{W}$. These indicate the existence of a trade-off between heat transfer rate and temperature difference (Carnot efficiency). However, a synergic increase of $A_{H E X}$ and $H_{T E}$ will continuously increase the power output. This trend is only limited by economic factors as illustrated in Fig. 5 or space availability rather than the performance itself. 

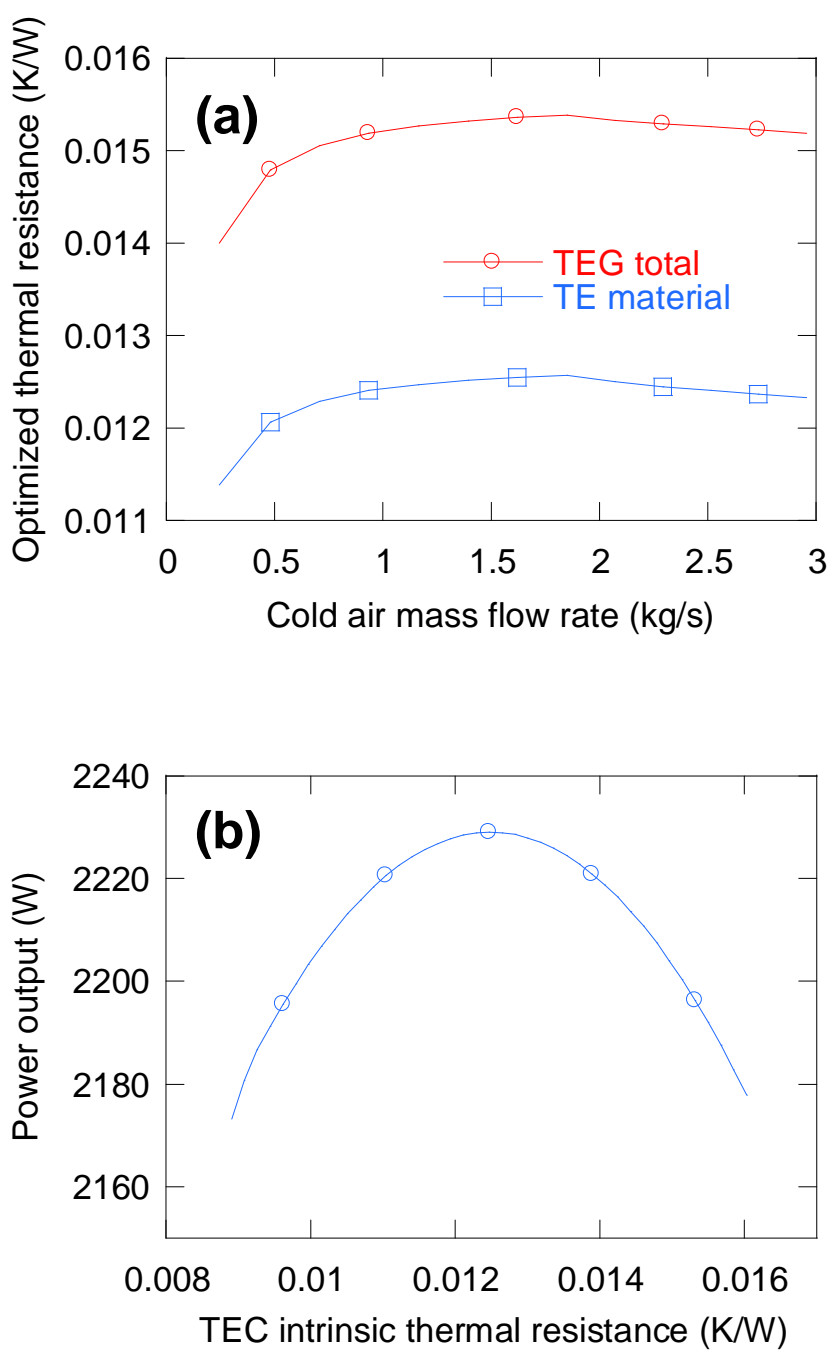

Fig. 12. (a) Comparison of the total thermal resistance of the TEGs and optimized thermal resistance of TE legs. (b) Influence of TE couple thermal resistance on the TEG performance.

To apply the proposed R-TEG in real world applications, the following details will need to be emphasized. A high-effectiveness gas phase heat exchanger needs to be integrated into the hot air stream to achieve a large energy scavenging rate with minimal irreversibility. For the precooler, since there is no requirement to accommodate TEMs, prime surface recuperators are generally favorable for their high overall heat transfer coefficient and low pressure drop. Further, integration of the precooler and the hot side heat exchanger of TEG 1 is also desirable to reduce 
losses at pipeline connections. The coolant supply is separated for the two sub-TEGs according to their hot side mass flow rate. An additional flow controller is needed for the regenerated heat carrier cycling in the abovementioned closed loop. TEG 2 running with the regenerated heat source is not limited to close to the hot air stream, and thus is flexible in its placement. These details can be readily implemented.

\section{Conclusions}

The regenerative concept was proposed for the first time for TEG applications. Using lowtemperature TE material $\mathrm{Bi}_{2} \mathrm{Te}_{3}$ only, an optimized regenerative TEG is shown to be capable of generating a similar amount of power compared to the TEG using high-temperature TE materials due to its higher energy scavenging capacity. The cost analyses for TEG system and pump power consumption supported the cost-effectiveness of the R-TEGs. The heat transfer rates and regenerated mass flow rates, as well as Carnot efficiency and local ZTs are analyzed in details to explain the performance of regenerative TEGs. Given the tremendous benefits of using low temperature TEMs for R-TEG including much lower-cost, much more reliable and available commercial modules, regenerative TEGs will represent a paradigm shift in the TEG research and development, and will contribute significantly to the use of TEGs for real world applications of converting waste heat to power.

\section{Acknowledgement}

The research was made possible with the financial support of the National Science Foundation (NSF), the US Department of Energy (DOE) [DE-EE0005432], and the National Aeronautics 
and Space Administration (NASA) Aeronautics Research Institute Seedling Fund. The authors also thank Dr. J.R. Salvador of General Motors R\&D for valuable discussions. 


\section{REFERENCES}

[1] Koumoto K. Oxide Thermoelectrics. Thermoelectr. Handb., CRC Press; 2005, p. 15-35. doi:10.1201/9781420038903.ch35.

[2] Poon GJ. Chapter 2 Electronic and thermoelectric properties of Half-Heusler alloys. Semicond Semimetals 2001;70:37-75. doi:10.1016/S0080-8784(01)80136-8.

[3] Sales BC, Mandrus D, Williams RK. Filled Skutterudite Antimonides: A New Class of Thermoelectric Materials. Science (80- ) 1996;272:1325-8.

[4] Scherrer S, Scherrer H. Bismuth Telluride, Antimony Telluride, and Their Solid Solutions. CRC Handb. Thermoelectr., CRC Press; 1995. doi:10.1201/9781420049718.ch19.

[5] Vining C. Silicon Germanium. CRC Handb. Thermoelectr., CRC Press; 1995. doi:10.1201/9781420049718.ch28.

[6] Crane DT, LaGrandeur JW. Progress Report on BSST-Led US Department of Energy Automotive Waste Heat Recovery Program. J Electron Mater 2010;39:2142-8. doi:10.1007/s11664-009-0991-0.

[7] Favarel C, Bédécarrats J-P, Kousksou T, Champier D. Experimental analysis with numerical comparison for different thermoelectric generators configurations. Energy Convers Manag 2015;107:114-22. doi:10.1016/j.enconman.2015.06.040.

[8] Ikoma K, Munekiyo M, Furuya K, Kobayashi M, Izumi T, Shinohara K. Thermoelectric module and generator for gasoline engine vehicles. Thermoelectr. 1998. Proc. ICT 98. XVII Int. Conf., 1998, p. 464-7. doi:10.1109/ICT.1998.740419.

[9] Karri MA, Thacher EF, Helenbrook BT. Exhaust energy conversion by thermoelectric generator: Two case studies. Energy Convers Manag 2011;52:1596-611. doi:10.1016/j.enconman.2010.10.013.

[10] Kim H, Kim W. A way of achieving a low $\$ / W$ and a decent power output from a thermoelectric device. Appl Energy 2015;139:205-11. 
doi:10.1016/j.apenergy.2014.11.040.

[11] Liang X, Sun X, Tian H, Shu G, Wang Y, Wang X. Comparison and parameter optimization of a two-stage thermoelectric generator using high temperature exhaust of internal combustion engine. Appl Energy 2014;130:190-9.

doi:10.1016/j.apenergy.2014.05.048.

[12] Merotto L, Fanciulli C, Donde R, De Iuliis S. Study of a thermoelectric generator based on a catalytic premixed meso-scale combustor. Appl Energy 2016;162:346-53. doi:10.1016/j.apenergy.2015.10.079.

[13] Rasfuldi R, Kotani Y, Kansha Y, Ishizuka M, Tsutsumi A. Self-heat recuperative heat circulation processing with thermoelectric device. Appl Energy 2014;160:836-42. doi:10.1016/j.apenergy.2015.03.055.

[14] Rowe DM, Smith J, Thomas G, Min G. Weight Penalty Incurred in Thermoelectric Recovery of Automobile Exhaust Heat. J Electron Mater 2011;40:784-8. doi:10.1007/s11664-011-1571-7.

[15] Schock H, Brereton G, Case E, D’Angelo J, Hogan T, Lyle M, et al. Prospects for Implementation of Thermoelectric Generators as Waste Heat Recovery Systems in Class 8 Truck Applications. J Energy Resour Technol 2013;135:22001. doi:10.1115/1.4023097.

[16] Soprani S, Haertel JHK, Lazarov BS, Sigmund O, Engelbrecht K. A design approach for integrating thermoelectric devices using topology optimization. Appl Energy 2016;176:49-64. doi:10.1016/j.apenergy.2016.05.024.

[17] Thacher EF, Helenbrook BT, Karri MA, Richter CJ. Testing of an automobile exhaust thermoelectric generator in a light truck. Proc Inst Mech Eng Part D J Automob Eng 2007;221:95-107. doi:10.1243/09544070JAUTO51.

[18] Wijesekara W, Rezania A, Rosendahl L. Simple engineering design for complex thermoelectric generators based on reduced current approach. Energy 2015;86:455-66. doi:10.1016/j.energy.2015.04.058. 
[19] Yang J, Stabler FR. Automotive Applications of Thermoelectric Materials. J Electron Mater 2009;38:1245-51. doi:10.1007/s11664-009-0680-z.

[20] Zhang Y, Cleary M, Wang X, Kempf N, Schoensee L, Yang J, et al. High-temperature and high-power-density nanostructured thermoelectric generator for automotive waste heat recovery. Energy Convers Manag 2015;105:946-50.

doi:10.1016/j.enconman.2015.08.051.

[21] Fateh H, Baker CA, Hall MJ, Shi L. High fidelity finite difference model for exploring multi-parameter thermoelectric generator design space. Appl Energy 2014;129:373-83. doi:10.1016/j.apenergy.2014.04.088.

[22] Gou X, Xiao H, Yang S. Modeling, experimental study and optimization on lowtemperature waste heat thermoelectric generator system. Appl Energy 2010;87:3131-6. doi:http://dx.doi.org/10.1016/j.apenergy.2010.02.013.

[23] Heghmanns A, Beitelschmidt M. Parameter optimization of thermoelectric modules using a genetic algorithm. Appl Energy 2015;155:447-54. doi:10.1016/j.apenergy.2015.06.034.

[24] Högblom O, Andersson R. A simulation framework for prediction of thermoelectric generator system performance. Appl Energy 2016;180:472-82.

doi:10.1016/j.apenergy.2016.08.019.

[25] Ma T, Lu X, Pandit J, Ekkad S V., Huxtable ST, Deshpande S, et al. Numerical study on thermoelectric-hydraulic performance of a thermoelectric power generator with a plate-fin heat exchanger with longitudinal vortex generators. Appl Energy 2015:1-12. doi:10.1016/j.apenergy.2016.01.078.

[26] Stevens RJ, Weinstein SJ, Koppula KS. Theoretical limits of thermoelectric power generation from exhaust gases. Appl Energy 2014;133:80-8. doi:10.1016/j.apenergy.2014.07.075.

[27] Wang Y, Dai C, Wang S. Theoretical analysis of a thermoelectric generator using exhaust gas of vehicles as heat source. Appl Energy 2013;112:1171-80.

doi:10.1016/j.apenergy.2013.01.018. 
[28] Yazawa K, Koh YR, Shakouri A. Optimization of thermoelectric topping combined steam turbine cycles for energy economy. Appl Energy 2013;109:1-9.

doi:10.1016/j.apenergy.2013.03.050.

[29] Zhang T. New thinking on modeling of thermoelectric devices. Appl Energy 2016;168:65-74. doi:10.1016/j.apenergy.2016.01.057.

[30] Dresselhaus MS, Chen G, Tang MY, Yang RG, Lee H, Wang DZ, et al. New Directions for Low-Dimensional Thermoelectric Materials. Adv Mater 2007;19:1043-53. doi:10.1002/adma.200600527.

[31] Garg J, Bonini N, Kozinsky B, Marzari N. Role of Disorder and Anharmonicity in the Thermal Conductivity of Silicon-Germanium Alloys: A First-Principles Study. Phys Rev Lett 2011;106:45901. doi:10.1103/PhysRevLett.106.045901.

[32] Pei Y, Shi X, LaLonde A, Wang H, Chen L, Snyder GJ. Convergence of electronic bands for high performance bulk thermoelectrics. Nature 2011;473:66-9.

[33] Voneshen DJ, Refson K, Borissenko E, Krisch M, Bosak A, Piovano A, et al. Suppression of thermal conductivity by rattling modes in thermoelectric sodium cobaltate. Nat Mater 2013;12:1028-32.

[34] Zhao L-D, Tan G, Hao S, He J, Pei Y, Chi H, et al. Ultrahigh power factor and thermoelectric performance in hole-doped single-crystal SnSe. Science (80- ) 2016;351:141-4.

[35] Venkatasubramanian R, Siivola E, Colpitts T, O’Quinn B. Thin-film thermoelectric devices with high room-temperature figures of merit. Nature 2001;413:597-602. doi:10.1038/35098012.

[36] Evident Thermoelectrics Inc. TEG-HH-8-1.0 Thermoelectric Generator Module Specification n.d. http://www.evidentthermo.com/images/docs/TEG-HH8_module_spec_sheet.pdf (accessed May 1, 2016).

[37] Hu K, Chi K, Shih T, Schock H. Heat Transfer Enhancement in Thermoelectric-Power 
Generation. 47th AIAA Aerosp Sci Meet Incl New Horizons Forum Aerosp Expo 2009:117. doi:10.2514/6.2009-1210.

[38] Meng X, Suzuki RO. Simulation Analysis of Tilted Polyhedron-Shaped Thermoelectric Elements. J Electron Mater 2015;44:1469-76. doi:10.1007/s11664-014-3418-5.

[39] Hi-Z Technology Inc. HZ-20 Thermoelectric Module Datasheet n.d. http://www.hiz.com/uploads/2/3/0/9/23090410/hz-20_datasheet.pdf (accessed August 25, 2016).

[40] Zhao XB, Ji XH, Zhang YH, Zhu TJ, Tu JP, Zhang XB. Bismuth telluride nanotubes and the effects on the thermoelectric properties of nanotube-containing nanocomposites. Appl Phys Lett 2005;86:1-3. doi:10.1063/1.1863440.

[41] Rowe DM, Min G. Evaluation of thermoelectric modules for power generation. J Power Sources 1998;73:193-8. doi:10.1016/S0378-7753(97)02801-2.

[42] Yang J. Potential applications of thermoelectric waste heat recovery in the automotive industry. ICT 2005. 24th Int. Conf. Thermoelectr. 2005., 2005, p. 1-5. doi:10.1109/ICT.2005.1519911.

[43] Yee SK, LeBlanc S, Goodson KE, Dames C. \$ per W metrics for thermoelectric power generation: beyond ZT. Energy Environ Sci 2013;6:2561. doi:10.1039/c3ee41504j.

[44] Joshi G, He R, Engber M, Samsonidze G, Pantha T, Dahal E, et al. NbFeSb-based p-type half-Heusler for power generation applications. Energy Environ Sci 2014;7:4070-6. doi:10.1039/C4EE02180K.

[45] Leblanc S, Yee SK, Scullin ML, Dames C, Goodson KE. Material and manufacturing cost considerations for thermoelectrics. Renew Sustain Energy Rev 2014;32:313-27. doi:10.1016/j.rser.2013.12.030.

[46] Yu S, Du Q, Diao H, Shu G, Jiao K. Start-up modes of thermoelectric generator based on vehicle exhaust waste heat recovery. Appl Energy 2015;138:276-90. doi:10.1016/j.apenergy.2014.10.062. 
[47] Montecucco A, Siviter J, Knox AR. The effect of temperature mismatch on thermoelectric generators electrically connected in series and parallel. Appl Energy 2014;123:47-54. doi:http://dx.doi.org/10.1016/j.apenergy.2014.02.030.

[48] Kumar S, Heister SD, Xu X, Salvador JR, Meisner GP. Thermoelectric Generators for Automotive Waste Heat Recovery Systems Part I: Numerical Modeling and Baseline Model Analysis. J Electron Mater 2013;42:665-74. doi:10.1007/s11664-013-2471-9.

[49] Kumar S, Heister SD, Xu X, Salvador JR, Meisner GP. Thermoelectric Generators for Automotive Waste Heat Recovery Systems Part II: Parametric Evaluation and Topological Studies. J Electron Mater 2013;42:944-55. doi:10.1007/s11664-013-2472-8.

[50] Huang S, Xu X. Parametric Optimization of Thermoelectric Generators for Waste Heat Recovery. J Electron Mater 2016. doi:10.1007/s11664-016-4740-x.

[51] Kumar S, Heister SD, Xu X, Salvador JR. Optimization of Thermoelectric Components for Automobile Waste Heat Recovery Systems. J Electron Mater 2015;44:3627-36. doi:10.1007/s11664-015-3912-4.

[52] Bergman TL, Incropera FP, DeWitt DP, Lavine AS. Fundamentals of heat and mass transfer. John Wiley \& Sons; 2011.

[53] Kays WM, London AL. Compact heat exchangers. McGraw-Hill, New York, NY; 1984.

[54] Shah RK, Sekulic DP. Fundamentals of heat exchanger design. John Wiley \& Sons; 2003.

[55] Goldsmid HJ. Conversion Efficiency and Figure-of-Merit. CRC Handb. Thermoelectr., CRC Press; 1995. doi:10.1201/9781420049718.ch3.

[56] Tang X, Zhang Q, Chen L, Goto T, Hirai T. Synthesis and thermoelectric properties of ptype- and n-type-filled skutterudite RyMxCo4-xSb12(R:Ce,Ba,Y;M:Fe,Ni). J Appl Phys 2005;97. doi:10.1063/1.1888048.

[57] Rogl G, Grytsiv A, Bauer E, Rogl P, Zehetbauer M. Thermoelectric properties of novel skutterudites with didymium: DDy(Fe1-xCox)4Sb12 and DDy(Fe1-xNix)4Sb12. 
Intermetallics 2010;18:57-64. doi:10.1016/j.intermet.2009.06.005. 